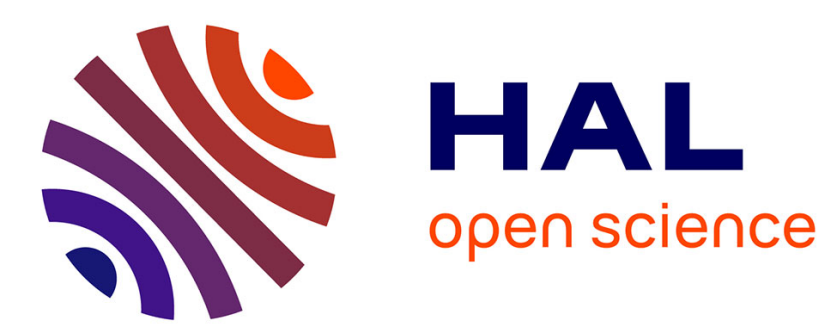

\title{
Direct Synthesis of Carbamoyl Fluorides by CO 2 Deoxyfluorination
}

\author{
Killian Onida, Anis Tlili
}

\section{To cite this version:}

Killian Onida, Anis Tlili. Direct Synthesis of Carbamoyl Fluorides by CO 2 Deoxyfluorination. Angewandte Chemie International Edition, 2019, 58 (36), pp.12545-12548. 10.1002/anie.201907354 . hal03008848

\section{HAL Id: hal-03008848 \\ https://hal.science/hal-03008848}

Submitted on 14 Dec 2020

HAL is a multi-disciplinary open access archive for the deposit and dissemination of scientific research documents, whether they are published or not. The documents may come from teaching and research institutions in France or abroad, or from public or private research centers.
L'archive ouverte pluridisciplinaire HAL, est destinée au dépôt et à la diffusion de documents scientifiques de niveau recherche, publiés ou non, émanant des établissements d'enseignement et de recherche français ou étrangers, des laboratoires publics ou privés. 


\title{
Direct Synthesis of Carbamoyl Fluoride through Unprecedented Deoxyfluorination of $\mathrm{CO}_{2}$
}

Killian Onida, and Anis Tlili*

\author{
K. Onida, Dr. A. Tlili \\ Institute of Chemistry and Biochemistry (ICBMS-UMR CNRS 5246) \\ Univ Lyon, Université Lyon 1, CNRS, CPE-Lyon, INSA \\ 43 Bd du 11 Novembre 1918, 69622 Villeurbanne, France \\ E-mail: anis.tlili@univ-lyon1.fr
}

\begin{abstract}
Herein a new concept for the direct synthesis of carbamoyl fluoride derivatives is disclosed. The developed methodology makes use of the interesting $\mathrm{CO}_{2}$ as cheap and abundant $\mathrm{C} 1$ source starting with a variety of amines in the presence of deoxyfluorinating reagent. The performed products are often obtained with excellent yields and the reactions are realized under mild conditions of pressure (1atm) and temperature (room temperature). The scalability of the reaction has been easily implemented demonstrating the efficiency of the developed process.
\end{abstract}

Fluorinated compounds have found a plethora of novel applications in all areas of life science technology. ${ }^{[1]}$ The particular interest in this class of compounds relies on their unique physical-chemical properties as they affect for example the lipophilicity of the molecule. ${ }^{[2]}$ Also, $\mathrm{C}-\mathrm{F}$ bonds can mimic $\mathrm{C}-\mathrm{H}$ bonds allowing a higher oxidation resistance more known as the "block effect ". ${ }^{[3]}$ Hence, it is not surprising that nowadays more than $20 \%$ of pharmaceutical and $40 \%$ of agrochemical active ingredients contain at least one fluorine atom. In this context, the perpetual development of new concepts for the introduction of fluorine or fluorine containing groups is highly appealing.

On the other hand, reducing the concentration of atmospheric $\mathrm{CO} 2$ is considered one of the most challenging tasks that scientists are facing nowadays. Furthermore, in recent years, this challenge has been found to be enormously complex since the impact of climate change is more obvious in daily life. In recognition of the current $\mathrm{CO}_{2}$ phenomenon, political bodies in most developing countries are implementing 
strategies to discourage carbon growth. In parallel, the transformation of the anthropogenic $\mathrm{CO}_{2}$ is an appealing field of research. From a chemical viewpoint, $\mathrm{CO}_{2}$ is a cheap and abundant feedstock. Nevertheless, its transformation as a C1 source constitutes a major challenge to modern organic chemistry evoked by its thermodynamic stability and kinetic inertness. To date, a handful of industrial processes make use of $\mathrm{CO}_{2}$ as a $\mathrm{C} 1$ source. ${ }^{[4]}$ In this context, the developments of new transformations based on the use of $\mathrm{CO}_{2}$ are highly covetable. ${ }^{[5]}$ Thus, complementary to bulk industry efforts the valorization of $\mathrm{CO}_{2}$ has recently become more prominent in the fine chemical industry. For instance, the capability of amines to uptake/bind $\mathrm{CO}_{2}$ is of fundamental importance and is utilized industrially to remove $\mathrm{CO}_{2}$. In this regard, the valorisation of amine/ $\mathrm{CO}_{2}$ adduct have been used as

a starting material in the presence of reductants for the synthesis of high valuable chemicals including formamides derivatives, methyl amines etc [6] [7]

We envisioned that the synthesis of new fluorinated molecules making use of $\mathrm{CO}_{2}$ would constitute even a higher added value in comparison to the state of the art. Herein we report an unprecedented catalyst-free synthesis of carbamoyl fluorides starting from amines and by using $\mathrm{CO}_{2}$ as a $\mathrm{C}_{1}$ source in the presence of a deoxyfluorinating reagent (Scheme 1). Worth noting, carbamoyl fluoride could be accessed by reacting amines with high pressure of Carbonyl fluoride or by reacting difluorocarbene with Hydroxylamines. ${ }^{[8]}$

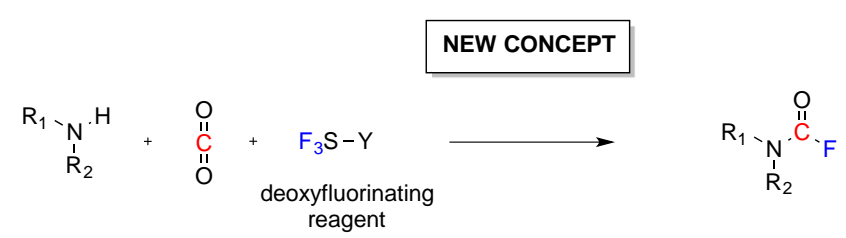

Scheme 1. General scheme for the new concept

From a conceptual standpoint, the deoxyfluorination of $\mathrm{CO}_{2}$ will constitute the key of success to achieve our goal furnishing the corresponding carbamoyl fluoride.

In order to confirm the feasibility of the concept we selected piperidine as model amine substrate. The first reaction was performed with DAST (1equiv.) in THF at room temperature under $1 \mathrm{~atm}$ of $\mathrm{CO}_{2}$. This initial attempt enabled the formation of the desired product in an encouraging yield of $39 \%$ (table 1, entry 1). With this proof of concept in hand, we decided to further investigate the reaction to improve the 
transformation outcome. To do so, we chose to investigate the solvent effect. In 1,4dioxane a lower reactivity was observed and only $24 \%$ of the desired product was formed (Table 1, entry 2). Further experiments demonstrated that also DMF as well as DMSO are less effective solvents for this transformation leading to low yields of $21 \%$ and $18 \%$, respectively. Interestingly, the yield increased to $48 \%$ when acetonitrile was used as solvent (table 1, entry 5). Furthermore, we have demonstrated that the reaction can be conducted under neat conditions although with inferior reaction outcome (table 1, entry 6). To further improve the reaction efficiency we tested the addition of additives. We decided to investigate the presence of an external base on the reaction outcome. The use of inorganic $\mathrm{Cs}_{2} \mathrm{CO}_{3}$ did not show any positive impact on the reaction yield (table 1, entry 7). Next we decided to investigate organic bases. While imidazole had a detrimental effect on the yield (table 1, entry 8), the use of DIPEA showed a positive impact (table 1, entry 9). NEt3 as well as 2,6-Lutidine proved to be enabling a more efficient transformation since respectively $72 \%$ and $74 \%$ yield were obtained (Table 1, entries 10 \& 11). Finally, an excellent yield of $90 \%$ was reached when DMAP was used as added base (table 1, entry 12). Performing the reaction with only 0.5 equivalents of DAST resulted in only $42 \%$ yield. A control experiment was conducted in the absence of $\mathrm{CO}_{2}$ and did not lead to any product formation.

Table 1. Reaction optimisation

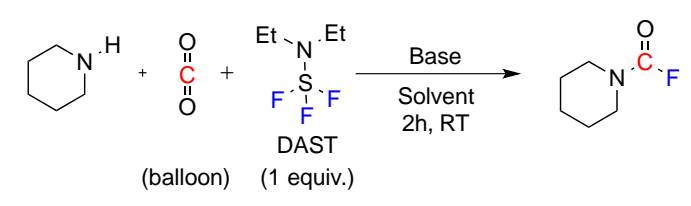

\begin{tabular}{cccc}
\hline Entry & Solvent & Base & $\begin{array}{c}\text { Yield } \\
(\%)^{\mathrm{b}}\end{array}$ \\
\hline 1 & THF & - & 39 \\
2 & $\begin{array}{c}1,4- \\
\text { dioxane }\end{array}$ & - & 24 \\
3 & DMF & - & 21
\end{tabular}




$\begin{array}{cccc}4 & \text { DMSO } & - & 18 \\ 5 & \text { ACN } & - & 48 \\ 6 & - & - & 24 \\ 7 & \text { ACN } & \mathrm{Cs}_{2} \mathrm{CO}_{3} & 45 \\ 8 & \text { ACN } & \text { Imidazol } & 33 \\ 9 & \text { ACN } & \text { DIPEA } & 51 \\ 10 & \text { ACN } & \text { NEt } 3 & 72 \\ 11 & \text { ACN } & 2,6- & 74 \\ & & \text { Lutidine } & \\ 12 & \text { ACN } & \text { DMAP } & 90 \\ 13 & \text { ACN } & \text { DMAP } & 42^{\mathrm{c}} \\ 14 & \text { ACN } & \text { DMAP } & 66^{d}\end{array}$

[a] Reactions were performed with Piperidine (1 mmol, 1 equiv.), DAST ( $1 \mathrm{mmol}, 1$ equiv.), CO2 (1 atm), base $(1 \mathrm{mmol})$ and solvent $(2 \mathrm{~mL})$. The reaction mixture was stirred at rt for 2 hours. [b] Determined by 19F NMR spectroscopy with PhOCF3 as an internal standard. [c] Reaction performed with 0.5 equiv. of DAST. [d] Reaction performed with 0.5 equiv. of DMAP. DAST=Diethylaminosulfur trifluoride. DIPEA=N,NDiisopropylethylamine. DMAP $=4$-Dimethylaminopyridine .

The testing of other common deoxyfluorinating agents such as XtalFluor-E, XtalFluor-M ${ }^{[9]}$ as well as Fluolead ${ }^{[10]}$ led to only moderate yield between $24 \%$ to $36 \%$ (table 2). It has been demonstrated that an exogenous fluoride source is enhances the performance of XtalFluor-E and XtalFluor-M. Indeed, in our case adding 1 equivalent of $3 \mathrm{HF}$.Et $3 \mathrm{~N}$ improved the reaction outcome singificantly and yields up to $60 \%$ was obtained. However, the latter results still fall short of those observed with DAST.

With the best conditions in hand, we investigated the reaction scope under the optimized reaction conditions. Cyclic piperidine, morpholine as well as $\mathrm{N}$-methylpiperazine furnished the desired product with excellent yields (up to $99 \%$, products 2 a, 2b and 2c, Scheme 2). Interestingly, BOC-protected piperazine underwent fluorocarbonylation with excellent reaction outcome (90\%, product $\mathbf{2 d}$ ) Noteworthy, 
product $\mathbf{2} \mathbf{d}$ has been characterized by $\mathrm{X}$-ray analysis. When starting from $4-(\mathrm{N}$-Bocamino)piperidine $1 \mathrm{e}$ was isolated with a synthetically useful yield of $51 \%$ (product $\mathbf{2 e}$, Scheme 2). Notably, the reaction proceed with high selectivity since only transformation of the cyclic nitrogen was observed. The corresponding structure has been confirmed by Hoesy NMR and unambiguously by X-ray analysis. Piperazine substituted with pyridine or 4-chlorobenzene was converted into their corresponding carbamoyl derivatives $\mathbf{2 g}$ and $\mathbf{2 h}$ with excellent reaction outcome. Tetrahydroisoquinoline 1i was transformed into its corresponding product with $90 \%$ yield. Interestingly, the presence of internal alkene is also tolerated and product $2 \mathrm{j}$ has been obtained in almost quantitative yield. Moreover, methylanilines were successfully transformed into their carbamoyl analogues in moderate to very good yields (products 2k, 2I, 2m). Benzylic amines are also compatible with this methodology and were converted successfully even in the presence of ester functionality (product 20) although in low yield. Interestingly, our protocol is applicable to bioactive compounds. Nortriptyline and Desipramine was converted to their corresponding carbamoyl compounds $2 \mathrm{~s}$ and $\mathbf{2 t}$ in excellent yields of up to $99 \%$. It should be mentioned that the respective starting materials were employed as hydrochloride salts in conjunction with of 2 equivalents of DMAP.

Table 2. Evaluation of deoxyfluorinating agents $^{a}$
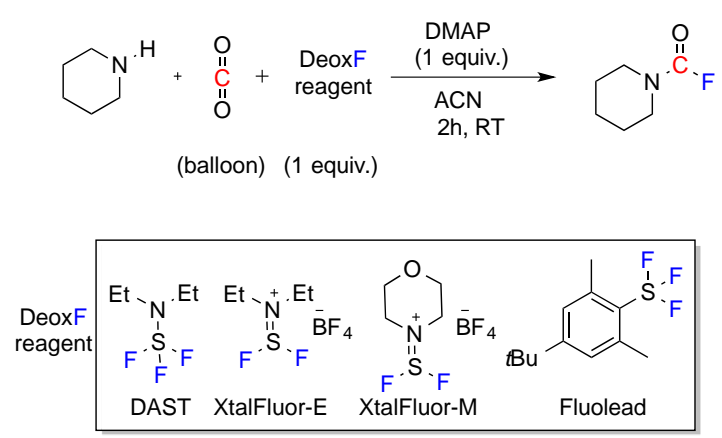


\begin{tabular}{ccc}
\hline Entry & $\begin{array}{c}\text { DeoxF } \\
\text { reagent }\end{array}$ & Yield (\%) $^{\mathrm{b}}$ \\
\hline 1 & DAST & 90 \\
2 & XtalFluor-E & $24,46^{\mathrm{c}}$ \\
3 & XtalFluor-M & $30,60^{\mathrm{c}}$ \\
4 & Fluolead & 36
\end{tabular}

[a] Reactions were performed with Piperidine (1 mmol, 1 equiv.), DeoxF reagent (1 mmol, 1 equiv.), $\mathrm{CO}_{2}$ (1 atm), DMAP (1 mmol) and $\mathrm{ACN}(2 \mathrm{~mL})$. The reaction mixture was stirred at it for 2 hours. [b] Determined by ${ }^{19} \mathrm{~F} \mathrm{NMR} \mathrm{spectroscopy} \mathrm{with} \mathrm{PhOCF}_{3}$ as an internal standard. [c] Reaction performed in the presence of 3HF.Et $3 \mathrm{~N}$ (1equiv., 0.33 $\mathrm{mmol})$.

Runing the experiment with an hydroxylated amine 1u, 4-Piperidine-methanol, furnishes the desired product $\mathbf{2} \mathbf{u}$ as well as a deoxyfluorinated product $\mathbf{2} \mathbf{u}$ ' both in low yield. 


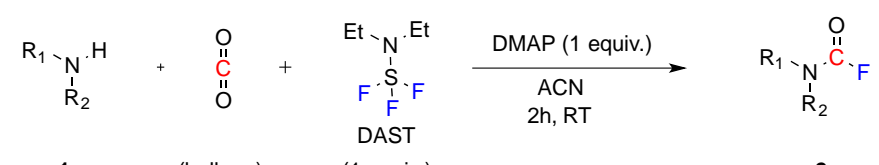

1 (balloon) (1 equiv.) 2

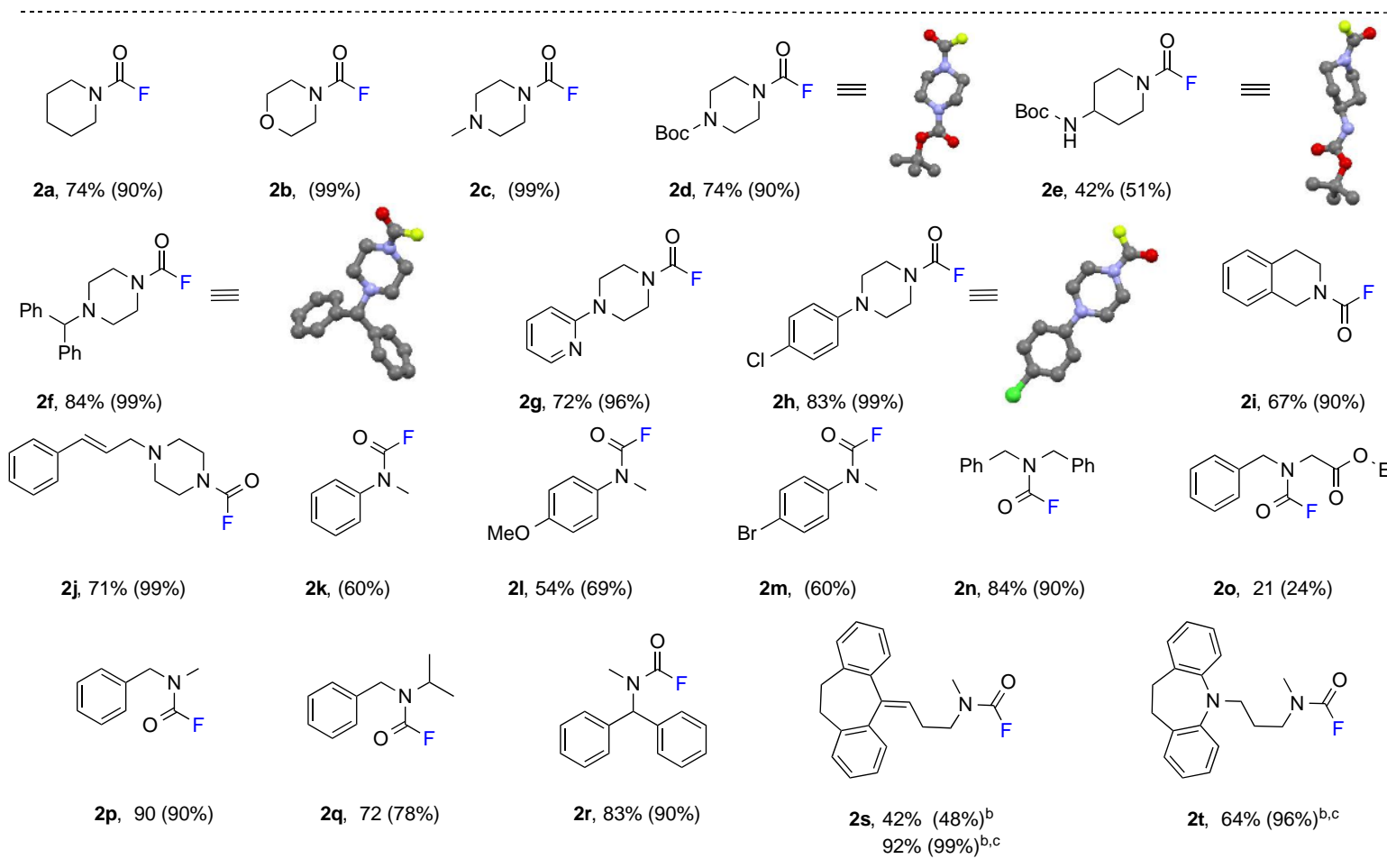

Scheme 2. [a] Reactions were performed with amine ( $1 \mathrm{mmol}, 1$ equiv.), DAST (1 mmol, 1 equiv.), $\mathrm{CO}_{2}$ (1 atm), DMAP (1 mmol) and ACN (2 mL) unless otherwise noted. The reaction mixture was stirred at it for 2 hours. Yields shown are those of isolated products; yields determined by ${ }^{19} \mathrm{~F}$ NMR spectroscopy with $\mathrm{PhOCF}_{3}$ as internal standard are shown in parentheses. [b] $\mathrm{HCl}$ salt. [c] Reaction performed with 2 equiv. of DMAP.

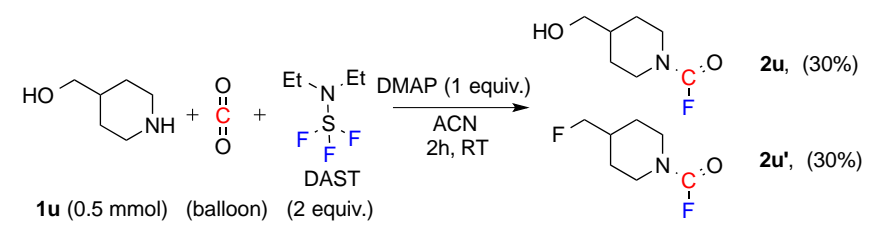

Scheme 3. Reaction with hydroxylated amine: yields determined by ${ }^{19} \mathrm{~F} N M R$ spectroscopy with $\mathrm{PhOCF}_{3}$ as internal standard

$$
20 \mathrm{mmol} \text { (balloon) }
$$

Scheme 4. Scale-up experiment 
In order to demonstrate the applicability of the reaction, we performed a scale-up experiment. Amine 1f $(20 \mathrm{mmol})$ underwent complete conversion and $4.3 \mathrm{~g}$ of the corresponding product $2 \mathbf{f}$ could be isolated (72\% yield, Scheme 4$)$.

In order to further explore the versatility of our methodology we investigated the reaction in the presence of ${ }^{13} \mathrm{CO}_{2}$. This approach allows for the direct access of radiolabeled bioactive reagents as demonstrated for Notriptyline hydrochloride as well as Desipramine hydrochloride. The respective ${ }^{13} \mathrm{C}$-labelled carbamoyl analogues were obtained in very good to excellent isolated yields (Scheme 5)

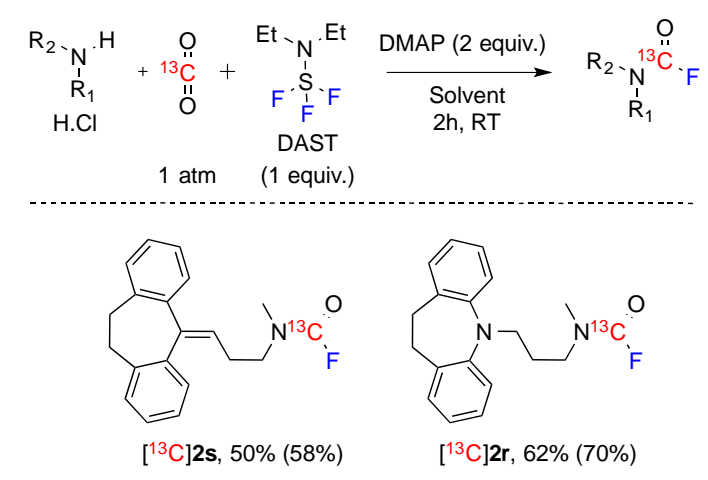

Scheme 5. Direct formation of $\mathrm{N}-{ }^{13} \mathrm{COF}$ by using ${ }^{13} \mathrm{CO}_{2}$ : [a] Reactions were performed with amine ( $1 \mathrm{mmol}, 1$ equiv.), DAST ( $1 \mathrm{mmol}, 1$ equiv.), $\mathrm{CO}_{2}$ ( $\left.1 \mathrm{~atm}\right)$, DMAP ( $1 \mathrm{mmol}$ ) and $\mathrm{ACN}(2 \mathrm{~mL})$.

From a mechanistic standpoint, it is important to note that we observed during the establishment of the reactions that upon mixture of an amine with $\mathrm{CO}_{2}$ a subsequent formation of salt takes place. Obviously, it is well documented that the formation of carbamate could take place (Intermediate A, Scheme 7). In order to confirm the hypothesis that DMAP is playing only a role of base we decided to investigate the reaction with the deprotonated amine. To do so, we performed the reaction with $n$ BuLi (Scheme 6). Herein the desired product could be obtained in $80 \%$ yield.

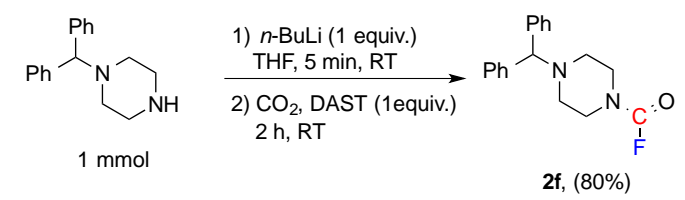

Scheme 6. Synthesis of Carbamoyl fluoride $2 \mathrm{f}$ in the presence of strong base 
In light of the obtained preliminary mechanistic investigations, we could propose the following mechanism (Scheme 7). Amine reacts with $\mathrm{CO}_{2}$ to form the carbamate $\mathbf{A}$. this later could react with DAST to form intermediate $\mathbf{B}$ and the starting amine is regenerated in the presence of a base. The desired product is generated form intermediate B either via an inter/ or intramolecular fluorine attack and diethylsulfuramidous fluoride $\mathbf{C}$ that we identify in fluorine NMR.

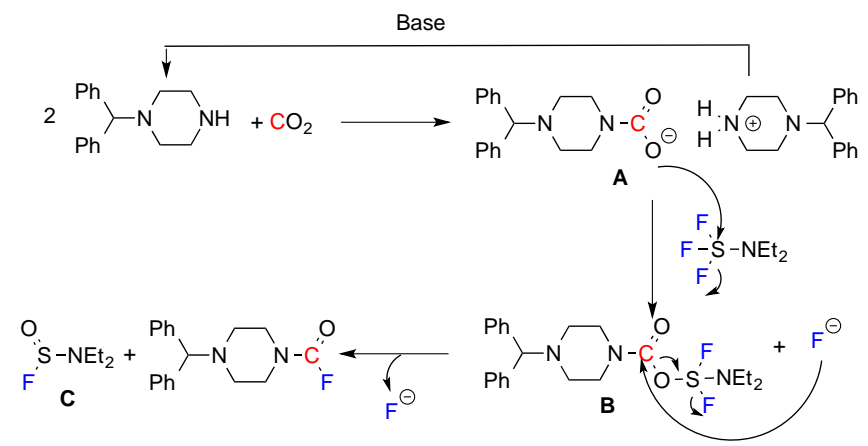

Scheme 7. Proposed mechanism

In conclusion, we demonstrated that carbamoyl fluorides derivatives could be obtained for the first time starting with amines and by using $\mathrm{CO}_{2}$ as a $\mathrm{C} 1$ source in conjunction with a deoxyfluorinating reagent. The reactions are performed under mild conditions of pressure (1atm) and temperature (room temperature) and the scope encompasses a wide range of starting amines derivatives. Moreover, the scalability of the reaction was demonstrated without any loose in the reaction outcome. Finally, the direct access to radiolabeled bioactive reagents was also demonstrated by using ${ }^{13} \mathrm{CO}_{2}$.

\section{Experimental Section}

Typical Procedure: Synthesis of Piperidine-1-carbonyl fluoride 2a: to a flamedried Schlenk flask were added DMAP (122 mg, $1.0 \mathrm{mmol}, 1.0$ equiv.). The flask was evacuated and back-filled with $\mathrm{CO}_{2} 3$ times, and then dry ACN $(2 \mathrm{~mL})$ was added by syringe. Then, the amine $(1.0 \mathrm{mmol}, 1.0$ equiv) and the DAST (dropwise) $(1.0 \mathrm{mmol}$, 
1.0 equiv.) were successively added to the Schlenk flask equipped with a balloon of $\mathrm{CO}_{2}$. The reaction mixture was stirred at $25^{\circ} \mathrm{C}$ for $2 \mathrm{~h}$ (conversion is checked by ${ }^{19} \mathrm{~F}$ $\mathrm{NMR}$ with $\mathrm{PhOCF}_{3}$ as internal standard). The resulting mixture was diluted with ether $(10 \mathrm{~mL})$ and water $(2 \mathrm{~mL})$. Following phase separation, the aqueous layer was extracted with ether $(3 \times 5 \mathrm{~mL})$. The resulting organic layer was washed with brine (1 $x 2 \mathrm{~mL}$ ), The organic layer was dried over anhydrous $\mathrm{MgSO}_{4}$ and evaporated under reduced pressure (rotary evaporator). The residue was purified by column chromatography to give the desired product in $74 \%$ as a colorless liquid.

\section{Acknowledgements}

This work was supported by the CNRS, COLUMN, ICL (Institut de Chimie de Lyon). We thank Dr. Guillaume Pilet (Université Lyon 1) for collecting the crystallographic data. We are grateful to Dr. E. Métay, Pr. J. Leclaire and Pr. A. Amgoune (ICBMS Lyon) for fruitful discussion

Keywords: Fluorination - Carbon dioxide $\cdot$ Amines $•$ Deoxyfluorination $•$ Deoxyfluorinating agent

[1] a) in Fluorine in Life Sciences: Pharmaceuticals, Medicinal Diagnostics, and Agrochemicals. (Eds.: G. Haufe, F. Leroux), Elsevier Science, London, United Kingdom, 2018, pp. 459-518.e) P. Kirsch in Modern Fluoroorganic Chemistry, Wiley-VCH, Wheineim, 2013; f) D. O'Hagan, Chem. Soc. Rev. 2008, 37, 308-319.

[2] a) A. Leo, C. Hansch, D. Elkins, Chem. Rev. 1971, 71, 525-616; b) L. Bruno, W. Zhong, C. Guillaume, P. Vincent, F. C. Q., W. Neil, W. W. Alex, Angew. Chem. Int. Ed. 2016, 55, 674-678; Angew. Chem. 2016, 128, 684-688.

[3] W. K. Hagmann, J. Med. Chem. 2008, 51, 4359-4369.

[4] S. Dabral, T. Schaub, Adv. Synth. Catal. 2019, 361, 223-246.

[5] a) J. Artz, T. E. Müller, K. Thenert, J. Kleinekorte, R. Meys, A. Sternberg, A. Bardow, W. Leitner, Chem. Rev. 2018, 118, 434-504; b) J. Klankermayer, S. Wesselbaum, K. Beydoun, W. Leitner, Angew. Chem. Int. Ed. 2016, 55, 72967343; Angew. Chem. 2016, 128, 7416-7467.

[6] a) Y. Li, X. Cui, K. Dong, K. Junge, M. Beller, ACS Catalysis 2017, 7, 1077-1086;

b) A. Tlili, E. Blondiaux, X. Frogneux, T. Cantat, Green Chem. 2015, 17, 157-168; 
c) A. Tlili, X. Frogneux, E. Blondiaux, T. Cantat, Angew. Chem. Int. Ed. 2014, 53, 2543-2545. Angew. Chem. 2014, 126, 2577-2579.

[7] a) C. Das Neves Gomes, O. Jacquet, C. Villiers, P. Thuéry, M. Ephritikhine, T. Cantat, Angew. Chem. Int. Ed. 2012, 51, 187-190; Angew. Chem. 2012, 124, 191 194. b) O. Jacquet, C. Das Neves Gomes, M. Ephritikhine, T. Cantat, J. Am. Chem. Soc. 2012, 134, 2934-2937; c) Y. Li, X. Fang, K. Junge, M. Beller, Angew. Chem. Int. Ed. 2013, 52, 9568-9571; Angew. Chem. 2013, 125, 9747-9750; d) Y. Li, I. Sorribes, T. Yan, K. Junge, M. Beller, Angew. Chem. Int. Ed. 2013, 52, 1215612160; Angew. Chem. 2013, 125, 12378-12382; e) O. Jacquet, X. Frogneux, C. Das Neves Gomes, T. Cantat, Chem. Sci. 2013, 4, 2127-2131; f) K. Beydoun, T. vom Stein, J. Klankermayer, W. Leitner, Angew. Chem. Int. Ed. 2013, 52, 95549557; Angew. Chem. 2013, 125, 9733-9736; g) Y. Li, T. Yan, K. Junge, M. Beller, Angew. Chem. Int. Ed. 2014, 53, 10476-10480; Angew. Chem. 2014, 126, 1064410648. h) S. Das, F. D. Bobbink, G. Laurenczy, P. J. Dyson, Angew. Chem. Int. Ed. 2014, 53, 12876-12879; Angew. Chem. 2014, 126, 13090-13093; i) H. Niu, L. Lu, R. Shi, C.-W. Chiang, A. Lei, Chem. Commun. 2017, 53, 1148-1151; j) M. Hulla, G. Laurenczy, P. J. Dyson, ACS Catalysis 2018, 8, 10619-10630.

[8] a) H. Quan, N. Zhang, X. Zhou, H. Qian, A. Sekiya, J. Fluor. Chem. 2015, 176, 26-30; b) H. Baars, J. Engel, L. Mertens, D. Meister, C. Bolm, Adv. Synth. Catal. 2016, 358, 2293-2299; c) The formation of carbamoyl fluroide has been observed also as a by product in a recent insitu generation of fluorophosgene: D. Petzold, P. Nitschke, F. Brandl, V. Scheidler, B. Dick, R. M. Gschwind, B. König, Chem. Eur. J. 2019, 25, 361-366.

[9] a) F. Beaulieu, L.-P. Beauregard, G. Courchesne, M. Couturier, F. LaFlamme, A. L'Heureux, Org. Lett. 2009, 11, 5050-5053; b) A. L'Heureux, F. Beaulieu, C. Bennett, D. R. Bill, S. Clayton, F. LaFlamme, M. Mirmehrabi, S. Tadayon, D. Tovell, M. Couturier, J. Org. Chem. 2010, 75, 3401-3411.

[10]T. Umemoto, R. P. Singh, Y. Xu, N. Saito, J. Am. Chem. Soc. 2010, 132, 1819918205. 